\title{
BIODIVERSITAS FAUNA SEBAGAI SALAH SATU INDIKATOR KESEHATAN HUTAN MANGROVE
}

\author{
Biodiversity Fauna As One of Mangrove Forest Health Indicators \\ Rizky Novia Sari ${ }^{\varpi}$, Rahmat Safe'i, Dian Iswandaru \\ Jurusan Kehutanan Universitas Lampung, Bandar Lampung \\ Jl. Prof. Sumantri Brojonegoro No.1 Bandar Lampung 35145 \\ ${ }^{\otimes}$ corresponding author: rizkynovia05@gmail.com
}

\begin{abstract}
Mangrove forests have a special function, namely as a green belt which is certainly very important for human life. Health of forests, especially mangrove forests, is often overlooked regarding their health conditions. The health condition of the mangrove forest is very influential on its sustainability, so to know its health, one of the indicators that can be used is fauna biodiversity. Fauna biodiversity can be known by using the FHM (Forest Health Monitoring) method to determine the diversity and condition of health status. Mangrove forest in Pasir Sakti Sub-District, East Lampung Regency has a diversity of 9 species of birds and 5 types of epifauna species. Based on this, the Mangrove Forest of Pasir Sakti District, East Lampung Regency has a good forest health status.
\end{abstract}

Key words: forest health, biodiversity, birds, epifauna.

\section{A. PENDAHULUAN}

Hutan mangrove Kecamatan Pasir Sakti Kabupaten Lampung Timur memiliki luas tutupan lahan 1.062,23 ha pada tahun 2013 (Yuliasamaya et al., 2014). Kondisi vegetasi didominasi oleh jenis api-api putih (Avicennia marina) dengan kondisi lahan basah berlumpur yang membentang seluas 296 ha. Menurut Sulistyowati (2009) hutan mangrove memiliki peran penting sebagai nursery area (tempat asuhan), feeding ground (tempat pemijahan) dan habitat dari berbagai macam ikan, udang, kerangkerang dan lain-lain. Selain itu, hutan mangrove merupakan sumber hara penting yang berfungsi sebagai sumber makanan bagi banyak spesies, seperti burungburung pantai.

Kondisi kesehatan hutan mangrove dapat diketahui dengan menilai indikator kesehatan hutan. Salah satu indikator yang digunakan dalam menilai kesehatan hutan mangrove adalah biodiversitas (keanekaragaman) fauna. Pengukuran kesehatan hutan merupakan langkah yang dapat dilakukan untuk menjamin fungsi dan manfaat hutan.

Keanekaragaman fauna yang digunakan dalam penelitian yaitu keanekaragaman burung dan epifauna. Burung dapat digunakan sebagai indikator perubahan ekosistem pada suatu lingkungan hal ini dikarenakan burung adalah satwa dengan tingkat mobilisasi tinggi dan dinamis sehingga dapat dengan cepat merespon perubahan yang terjadi di lingkungan (Gafur et al., 2016). Epifauna adalah salah satu komponen ekosistem mangrove yang juga bisa digunakan sebagai salah satu parameter biologi untuk menunjukkan kondisi suatu perairan. Hewan-hewan makrobentos sangat peka terhadap perubahan kualitas air tempat hidupnya, sehingga akan berpengaruh terhadap komposisi dan kelimpahannya (Muhammad et al., 2017).

Kesadaran tentang pentingnya kesehatan hutan dalam mencapai pengelolaan hutan yang lestari sampai saat ini masih kurang termasuk di Provinsi Lampung yang belum mendapat perhatian serius (Safe'i et al., 2019). Hutan mangrove di Kecamatan Pasir Sakti Kabupaten Lampung Timur perlu dilakukan penelitian terkait kesehatan hutan karena berada dalam kelola KPHL (Kesatuan Pengelolaan Hutan Lindung) Gunung Balak Kabupaten Lampung Timur, sehingga hasil penelitian dapat digunakan sebagai acuan dalam pengelolaan selanjutnya. Kondisi kesehatan hutan mangrove sangat berpengaruh terhadap keberlanjutan ekosistemnya. Oleh karena itu, sangat penting dilakukan penelitian untuk mengetahui status kondisi kesehatan hutan mangrove dengan menggunakan salah satu indikator dari kesehatan hutan mangrove yakni biodiversitas fauna berdasarkan indeks keanekaragaman. 


\section{METODE PENELITIAN}

Penelitian ini dilaksanakan pada bulan Desember 2018 yang berlokasi di Hutan Mangrove Kecamatan Pasir Sakti Kabupaten Lampung Timur. Lokasi ini dipilih karena memiliki areal yang luas dibandingkan dengan hutan mangrove lain di Provinsi Lampung. Selain itu kondisi ekosistem yang masih terjaga dan hutan mangrove ini dikelola oleh KPHL (Kesatuan Pengelolaan Hutan Lindung) Gunung Balak.

\section{Pengumpulan data}

Pengambilan data fauna dilakukan dengan metode FHM (Forest Helath Monitoring). Metode FHM adalah metode yang digunakan untuk penilaian kesehatan hutan, dimana dalam satu klaster plot terdiri dari empat plot. Tujuan FHM adalah menyediakan informasi kondisi hutan setiap tahun serta menilai status dan kondisi ekosistem hutan disemua lahan hutan. Data dikumpulkan dan dianalisis untuk mengetahui kondisi terbaru dari berbagai indikator ekosistem hutan. Indikator yang digunakan adalah biodiversitas fauna (burung dan epifauna). Informasi ini digunakan untuk mengambil keputusan manajemen pengelolaan hutan (Mangold, 1997).

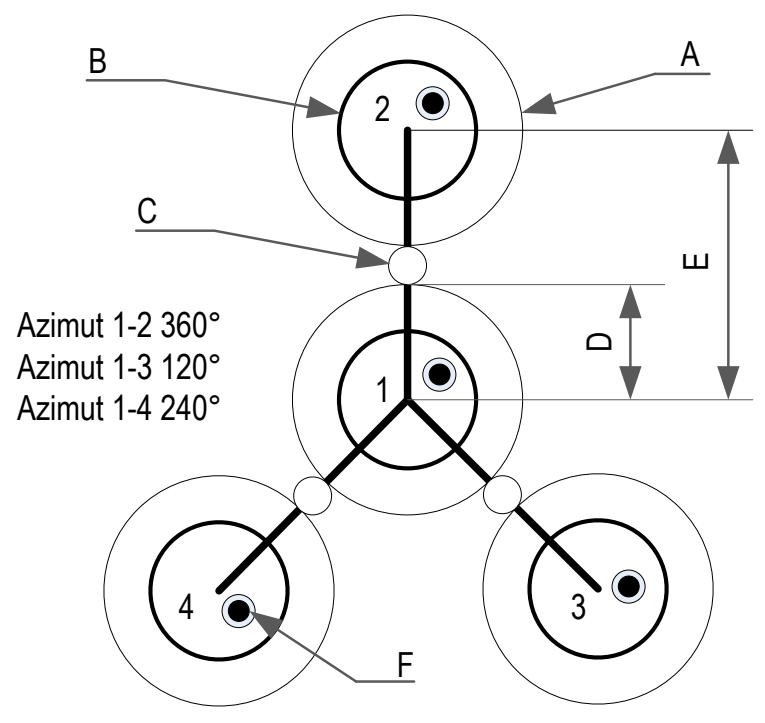

Gambar 1. Desain klaster-plot FHM (Mangold, 1997). Keterangan: $A=$ Annular plot jari-jari $17,95 \mathrm{~m}$; $B=$ subplot jarijari 7,32 m; C= titik contoh tanah; $\mathrm{D}=$ jarak titik contoh tanah dari titik pusat subplot adalah $18 \mathrm{~m}$; $\mathrm{E}=$ jarak antara titik pusat plot adalah 36,6 m; F = mikroplot jari-jari 2,07 m tiap azimut dan jarak dari titik pusat subplot adalah $3,66 \mathrm{~m}$.

Pengamatan burung hanya dilakukan pada titik pusat plot 1 selama 30 menit pada masing-masing klaster plot untuk mencegah terjadinya penghitungan ganda. Pengamatan dilakukan selama dua kali untuk setiap klasternya, yaitu pada pagi hari pukul 07.00-10.00 WIB dan sore hari pada pukul 15.00-17.00 WIB. Pemilihan waktu ini dilakukan karena pada pagi dan sore hari burung sedang aktif melakukan kegiatan, sehingga lebih mudah untuk menjumpai burung. Sedangkan untuk penghitungan epifauna dilakukan pada masing-masing plot disetiap klaster plotnya. Penentuan jumlah dan peletakan klaster plot penelitian berdasarkan stratified sampling intensitas sampling sebesar $0,009 \%$ sehingga dengan luasan yang ada yaitu 296 ha diperoleh sebanyak 6 klaster plot. Hal ini berdasarkan pada P.67/Menhut-II/2006 tentang Kriteria dan Standar Inventarisasi Hutan, bahwa dalam menggunakan metode bentuk petak ukur lingkaran, persegi empat, titik, dan jalur minimal intensitas sampling sebesar 0,0025\%. Sehingga intensitas sampling yang ditentukan oleh peneliti sebesar 0,009\% sudah dapat mewakili luasan hutan mangrove pada penelitian yang dilakukan. Metode FHM (Forest Health Monitoring) pengamatan fauna dapat dilihat pada Gambar 1.

\section{Analisis Data}

Analisis data kuantitatif dilakukan untuk memperoleh data keanekaragaman jenis burung dan epifauna, nilai skoring indikator dan nilai akhir kondisi kesehatan hutan mangrove. Rumus-yang digunakan dalam pengolahan data antara lain:

\section{Indeks keanekaragaman jenis $\left(H^{\prime}\right)$}

Keanekaragaman jenis suatu individu dapat ditentukan dengan menggunakan persamaan (1), yakni indeks keanekaragaman Shannon-Wiener (Odum, 1996)

$$
H^{\prime}=-\sum(P i \ln P i)
$$

Keterangan: $\mathrm{H}^{\prime}$ adalah indeks keanekaragaman jenis fauna; Piadalah ni/N; Ni adalah jumlah individu jenis ke-1; dan $\mathrm{N}$ adalah jumlah individu semua jenis.

\section{Nilai Skoring}

Nilai skoring ditentukan berdasarkan kategori nilai indeks keanekaragaman, yang terdiri dari 3 kategori yaitu (keanekaragaman rendah, sedang dan tinggi) menurut Odum (1996). Semakin tinggi nilai skor menunjukkan tingkat kesehatan hutan mangrove semakin tinggi. Kategori kondisi kesehatan hutan mangrove yaitu bagus (good), sedang (moderate), jelek (poor) (Safe'i \& Tsani, 2016). Kelas nilai untuk masing-masing kategori diperoleh berdasarkan penghitungan nilai akhir kondisi hutan mangrove (NKHm) pada masing-masing klaster plot.

\section{Nilai Akhir Kondisi Kesehatan Hutan Mangrove (NKHm)}

Menurut Safe'i dan Tsani (2016), nilai akhir kondisi kesehatan hutan merupakan hasil perkalian antara nilai tertimbang dengan nilai skor parameter dari indikator yang digunakan yaitu biodiversitas. Menurut Safe'i et al. (2013) nilai tertimbang merupakan parameter dari masing-masing indikator kesehatan mangrove. Nilai tertimbang indikator biodiversitas sebesar 0,33 (Safe'i et al., 2019). Nilai akhir 
kondisi kesehatan hutan mangrove dihitung dengan menggunakan persamaan (2).

$N K H m=\sum(N T X N S)$

Keterangan: $\mathrm{NKHm}$ adalah nilai akhir kondisi kesehatan hutan mangrove; NT adalah nilai tertimbang parameter dari indikator kesehatan hutan mangrove; NS adalah nilai skor parameter dari indikator kesehatan hutan mangrove.

\section{HASIL DAN PEMBAHASAN}

Keanekaragaman jenis burung dan epifauna yang terdapat di Hutan Mangrove Kecamatan Pasir Sakti Kabupaten Lampung Timur memiliki jenis burung dan epifauna yang relatif sama di setiap klaster plotnya. Tingkat keanekaragaman berbanding lurus dengan tingkat kelenturan, dimana semakin tinggi tingkat biodiversitas yang dimiliki dalam suatu hutan akan meningkatkan tingkat kelenturan hutan (Safe'i et al., 2018). Jumlah keseluruhan jenis burung dan epifauna yang dijumpai pada masing-masing klaster plot pada Tabel 1 . Jumlah jenis burung yang ditemukan dalam pengamatan sebanyak 8 jenis dan epifauna sebanyak 5 jenis. Jenis burung yang selalu ada dalam klaster plot adalah burung kuntul besar (Egretta alba) dan untuk jenis epifauna yang selalu ada dalam klaster plot adalah wideng (Sesarma spp). Menurut Noerdjito dan Maryanto (2001), burung kuntul besar ( $E$. alba) merupakan jenis burung famili Ardeidae yang dilindungi dari genus Egretta berdasarkan Peraturan Pemerintah nomor 7 tahun 1999 tentang Pengawetan Jenis Tumbuhan dan Satwa (Departemen Kehutanan, 1999) karena populasinya mengalami penurunan. Hal ini dapat menunjukkan bahwa kondisi hutan mangrove di Kecamatan Pasir Sakti Kabupaten Lampung Timur memiliki ekosistem yang masih terjaga. Hal ini sejalan dengan penelitian Angriana et al. (2018) bahwa burung sebagai salah satu komponen ekosistem memiliki hubungan timbal balik dan saling ketergantungan dengan lingkungannya.

Keanekaragaman fauna yang telah dijumpai di lokasi Hutan Mangrove Kecamatan Pasir Sakti Kabupaten Lampung Timur memiliki nilai keanekaragaman $\left(\mathrm{H}^{\prime}\right)$ terbesar 2,43 yang tergolong dalam kategori sedang dan terendah sebesar 0,45 yang tergolong dalam kategori rendah berdasarkan kriteria yang telah ditetapka oleh Odum (1996). Berdasarkan Tabel 2. maka nilai akhir kondisi kesehatan hutan mangrove dapat diketahui sebagaimana dijelaskan pada Tabel 3. dan Tabel 4. Setelah diketahui nilai akhir kondisi kesehatan hutan mangrove maka status kesehatan hutannya pun dapat diketahui.

Tabel 1. Keanekaragaman jenis avifauna dan epifauna di Hutan Mangrove Kecamatan Pasir Sakti, Kabupaten Lampung Timur, Provinsi Lampung.

\begin{tabular}{|c|c|c|c|c|}
\hline Famili & Jenis fauna & Nama ilmiah & Jumlah & $\begin{array}{l}\text { Klaster } \\
\text { plot }\end{array}$ \\
\hline \multirow[t]{4}{*}{ Ardeidae } & Kuntul besar & Egretta alba & 41 & $1,2,3,4,5,6$ \\
\hline & Kuntul kecil & Egretta garzetta & 16 & $2,3,4,5$ \\
\hline & Kokokan laut & Butorides striatus & 6 & 3 \\
\hline & Cangak abu & Ardea cinerea & 2 & 4,6 \\
\hline Phalacrocoracidae & Pecuk padi hitam & $\begin{array}{l}\text { Phalacrocorax } \\
\text { sulcirostris }\end{array}$ & 9 & $1,2,4$ \\
\hline \multirow[t]{2}{*}{ Alcedinidae } & Cekakak sungai & $\begin{array}{l}\text { Todiramphus } \\
\text { chloris }\end{array}$ & 1 & $\begin{array}{l}1 \\
5\end{array}$ \\
\hline & Raja udang biru & $\begin{array}{l}\text { Alcedo } \\
\text { coerulescens }\end{array}$ & 12 & $3,4,5,6$ \\
\hline Anatidae & Belibis kembang & $\begin{array}{l}\text { Dendrocygna } \\
\text { arcuata }\end{array}$ & 2 & 4,6 \\
\hline Ciconiidae & Bangau tong-tong & $\begin{array}{l}\text { Leptoptilos } \\
\text { javanicus }\end{array}$ & 1 & 6 \\
\hline Gobiidae & Ikan glodok & Periophthalmus sp. & 19 & 4,6 \\
\hline Limulidae & Mimi/ belangkas & Limulidae & 22 & $4,5,6$ \\
\hline Potamididae & Kerang bakau & $\begin{array}{l}\text { Telescopium } \\
\text { telescopium }\end{array}$ & 5.364 & $3,4,5,6$ \\
\hline Ellobiidae & Siput mangrove & $\begin{array}{l}\text { Cassidula } \\
\text { aurisfelis }\end{array}$ & 12.672 & $3,4,5,6$ \\
\hline \multirow[t]{2}{*}{ Sesarmae } & Wideng & Sesarma spp & 15.495 & $1,2,3,4,5,6$ \\
\hline & Jumlah Total & & 33.662 & \\
\hline
\end{tabular}


Tabel 2. Nilai keanekaragaman jenis fauna di wilayah Hutan Mangrove Kecamatan Pasir Sakti, Kabupaten Lampung Timur, Provinsi Lampung.

\begin{tabular}{cc}
\hline Klaster Plot FHM & $\begin{array}{c}\text { Nilai H' } \\
\text { (Keanekaragaman Jenis Fauna) }\end{array}$ \\
\hline 1 & 0,45 \\
2 & 1,00 \\
3 & 2,30 \\
4 & 2,43 \\
5 & 1,51 \\
6 & 1,68 \\
\hline
\end{tabular}

Sumber: Olahan data primer, 2018.

Keanekaragaman fauna yang telah ditemui dalam penelitian memiliki jumlah famili sebanyak 9 yang terdiri dari famili Ardaide, Phalacrocoracidae, Gobiidae, Limulidae, Potamididae, Ellobiidae, Alcedinidae, Anatidae, Portunidae dan Ciconiidae.

Tabel 3. Nilai kelas skor keanekaragaman jenis fauna di hutan mangrove, Kecamatan Pasir Sakti, Kabupaten Lampung Timur.

\begin{tabular}{ccccc}
\hline $\begin{array}{c}\text { Klaster } \\
\text { plot }\end{array}$ & $\begin{array}{c}\text { Nilai skor } \\
\text { (NS) } \\
\text { biodiversitas } \\
\text { fauna }\end{array}$ & $\begin{array}{c}\text { Nilai } \\
\text { tertimbang } \\
\text { (NT) } \\
\text { biodiversitas }\end{array}$ & $\begin{array}{c}\text { Nilai akhir } \\
\text { kondisi } \\
\text { kesehatan } \\
\text { hutan } \\
\text { mangrove } \\
(\text { NKHm) }\end{array}$ & $\begin{array}{c}\text { Status } \\
\text { Kesehatan }\end{array}$ \\
\hline 1 & 1 & & 0,33 & Jelek \\
2 & 2 & 0,33 & 0,66 & Jelek \\
3 & 5 & 0,33 & 1,65 & Baik \\
4 & 5 & 0,33 & 1,65 & Baik \\
5 & 3 & 0,33 & 0,99 & Sedang \\
6 & 4 & 0,33 & 1,32 & Baik \\
\hline
\end{tabular}

Tabel 4. Nilai ambang batas status kesehatan hutan mangrove.

\begin{tabular}{cc}
\hline Kelas nilai akhir & $\begin{array}{c}\text { Kategori kondisi kesehatan } \\
\text { hutan mangrove }\end{array}$ \\
\hline $0,30-0,76$ & Jelek \\
$0,77-1,20$ & Sedang \\
$1,20-1,65$ & Baik \\
\hline
\end{tabular}

Pada Tabel 3. diketahui bahwa status kesehatan hutan mangrove di Kecamatan Pasir Sakti Kabupaten Lampung Timur memiliki kondisi $50 \%$ baik, 16,67\% sedang dan 33,33\% dalam kondisi jelek. Kondisi ekosistem yang jelek berada pada klaster plot 1 dan 2, hal ini disebabkan karena pada klaster plot 1 dan 2 memiliki kondisi lantai hutan yang tidak tergenang dan menyebabkan beberapa epifauna tidak mampu bertahan hidup seperti kerang bakau (Telescopium telescopium), siput mangrove (Cassidula aurisfelis). Hamidy (2010) yang menyatakan bahwa beberapa jenis spesies dari kelompok moluska yang tergolong dalam epifauna lebih menyukai wilayah yang berair atau tergenang air dan sangat peka terhadap kondisi suatu perairan. Selain itu jenis burung pantai lebih menyukai wilayah yang berair, hal ini didukung oleh penelitian Iswandaru et al. (2018) bahwa kondisi hutan mangrove yang sebagian berair dan berlumpur dangkal sehingga sangat disukai oleh jenis burung untuk melakukan aktivitas harian. Begitu pula dengan epifauna yang keberadannya sangat dipengaruhi oleh kondisi air dan lumpur. Kelompok moluska mangrove sebagai bagian dari ekosistem hutan mangrove memiliki peran yang cukup penting yang secara langsung maupun tidak langsung mendukung fungsi-fungsi ekologis hutan mangrove. Beberapa spesies moluska seperti anggota Famili Potamididae, Neritidae, dan Cerithidae merupakan spesies-spesies yang menjadikan mangrove sebagai habitatnya. Famili Potamididae (Telescopium, Terebralia, dan Cerithidea) merupakan kelompok moluska asli hutan mangrove yang menghabiskan seluruh masa hidupnya di hutan mangrove (Insnaningsih \& Patria, 2018).

\section{KESIMPULAN}

Hutan mangrove di Kecamatan Pasir Sakti Kabupaten Lampung Timur memiliki nilai keanekaragaman $\left(\mathrm{H}^{\prime}\right)$ terbesar 2,43 yang tergolong dalam kategori sedang dan keanekaragaman terendah sebesar 0,45 yang tergolong dalam kategori rendah sehingga diperoleh nilai kondisi kesehatan hutan mangrove 50\% baik, $16,67 \%$ sedang dan $33,33 \%$ dalam kondisi jelek.

\section{DAFTAR PUSTAKA}

Angriana, P., Dewi, B.S., \& Winarno, G.D. 2018. Populasi dan pola sebaran burung kuntul besar (Egretta alba) di Lampung Mangrove Center. Jurnal Sylva Lestari, 6(3): 73-80.

Departemen Kehutanan. (1999). Peraturan Pemerintah Republik Indonesia Nomor 7 Tahun 1999 tentang Pengawetan Jenis Tumbuhan dan Satwa. Jakarta: Departemen Kehutanan.

Departemen Kehutanan. (2006). Lampiran Peraturan Menteri Kehutanan Nomor P.67/Menhut-II/2006 tentang Kriteria dan Standar Invemtarisasi Hutan. Jakarta: Departemen Kehutanan.

Gafur, A., Elhayat, L., \& Ikhsan, M. (2016). Asosiasi jenis burung pada kawasan hutan mangrove di anjungan kota palu. Jurnal Warta Rimba, 4(1): 42-48.

Hamidy R. 2010. Struktur dan keragaman komunitas kepiting di kawasan hutan mangrove stasiun kelautan Universitas Riau, Desa Purnama Dumai. IImu Lingkungan Journal of Enviromental Science, 2(4): 81- 91.

Insnaningsih, N.R., \& Patria, M.P. (2018). Peran komunitas moluska dalam mendukung fungsi kawasan mangrove di Tanjung Lesung, Pandeglang, Banten. Jurnal Biotropika, 6(2): 35-44.

Iswandaru, D., Khalil, A.A.R., Kurniawan, B., Pramana, R., Febryano, I.G., \& Winarno, G.D. (2018). Kelimpahan dan keanekaragaman jenis burung di hutan mangrove $\mathrm{KPHL}$ Gunung Balak. Indonesian Journal of Conservation: 7(1). 5762.

Mangold, R. (1997). Forest health monitoring: field methods guide (international-indonesia). Washington DC, Amerika Serikat: USDA Forest Service.

Muhammad, F., Izzati, M., \& Mukid, A.M. (2017). Makrobenthos sebagai indikator tingkat kesuburan tambak di pantai utara Jawa Tengah. Jurnal Bioma, 19(1): 38-46. 
Noerdjito M., \& Maryanto I. (2001). Jenis-Jenis Hayati yang Dilindungi Perundang-Undangan Indonesia. Bogor: Balitbang Zoologi, Puslitbang Biologi-LIPI dan the Nature Conservancy.

Odum, E.P. (1996). Dasar-dasar ekologi. Yogyakarta: Gadjah Mada University Press.

Safe'i, R. \& Tsani, K.M. (2016). Kesehatan Hutan: Penilaian Kesehatan Hutan Menggunakan Teknik Forest Health Monitoring. Yogyakarta: Plantaxia.

Safe'i, R., Erly, H., Wulandari, C., \& Kaskoyo, H. (2018). Analisis keanekaragaman jenis pohon sebagai salah satu indikator kesehatan hutan konservasi. Jurnal Perennial. 14(2). 32-36.
Safe'i, R., Hardjanto., Supriyanto, \& Sundawati, L. (2013). Pengembangan metode penilaian kesehatan hutan rakyat sengon (miq.) Barneby \& J.W. Grimes). Jurnal Penelitian Hutan Tanaman, 12(3): 175-187.

Safe'i, R., Wuladari, C., \& Kaskoyo, H. (2019). Penilaian kesehatan hutan pada berbagai tipe hutan di Provinsi Lampung. Jurnal Sylva Lestari, 7(1): 95-109.

Sulistyowati, H. (2009). Biodiversitas mangrove di Cagar Alam Pulau Sempu. Jurnal Saintek. 8(1). 59-61.

Yuliasamaya., Darmawan, A., \& Hilmanto, R. (2014). Perubahan tutupan hutan mangrove di Pesisir Kabupaten Lampung Timur. Jurnal Sylva Lestari, 2(3): 111-124. 